\title{
A study of the Teaching Methods of Improving English Listening Ability of the Students
}

\author{
Yan Zhang \\ Weifang University of Science and Technology, ShanDong ShouGuang, 262700,China.
}

Keywords: Junior middle school students; Listening ability; Reasons; Strategies.

\begin{abstract}
This paper mainly discusses how to improve students' listening ability in English listening and teaching. The article discusses the problem fro $m$ two aspects: 1 . In daily study, cultivate students listening skills from the aspects of training students' good psychological quality, helping students correct pronunciation and creating a certain environment, taking certain skills and so on. 2. Pay attention to extracurricular knowledge.
\end{abstract}

\section{Introduction}

As a kind of communication tool, English plays a pivotal role in society. One of the important goals of learning English is to express one's ideas freely and reach the purpose of communication. And this is based on the hearing.English cannot be used without listening. Improving the listening ability of middle school students is an essential link in middle school English learning. It is a direct result of the students' speaking, reading and writing abilities, but it is also the key to complete the task of middle school English teaching.

Listening is the most basic and important ability in English teaching. Listening is one of the important ways in the communication of people, and one of the important ways of learning English. The level of listening directly affects the overall level of English. Generally speaking, the level of listening should be synchronized with the development of English, which enhances the level of common. However, that is not the case, according to the learning and teaching experience, in the process of English learning, learners encounter more listening difficulties than reading and writing ones. The written English level of the students will always be higher than their level of hearing, which is caused by many reasons, such as the listening comprehension have been included in the exam, college entrance examination score and score is relatively high. And some of the students with poor hearing feel distress. Therefore, it is urgent to improve the middle school students' listening proficiency. How to improve the students' English listening is the problem that English teaching workers are discussing constantly. This paper attempts to analyze the factors that cause the poor level of students' listening, and to improve the listening ability of students.

\section{In the day learning from all aspects of the students' listening skills}

Cultivate students' good psychological quality. Of different character and unreasonable intelligence of junior high school students in English learning, there is a completely different feeling, which requires teachers in English listening teaching process to pay attention to in accordance with their aptitude, adopting different teaching methods for different students, thus to enable studen ts to be full of self-confidence. The design of a wide variety of listening test content in modem English textbooks will inevitably add students' psychological pressure and psychological withdrawal. In this way, students in anxiety cannot clearly heard listening tests, which requires the majority of teachers to help students get rid of worries in the implementation of English Listening Teaching and to help students proper psychological debugging work in a timely manner, to, eliminate tension, teach students self adjustment, so that students can be confident and relax to communicate with others, in exchange for listening training. In addition, in the usual English teaching, teachers should pay attention 
to the mainten ance of students' self-esteem and self-confidence, on the learning process of high school students make progress to timely encouragement and affirmation, making every student be able to form a good psychological quality, resulting in English listening learning and always be full of confidence.

Help students pronounce correctly. There are many pronunciation which is similar, but have very different meanings of words, in the beginning of the teaching, such as: vowel duration [u:] and [u], [I:] and [i], from the tongue placed position, airflow, from the aspects of explanation, repeated over and over again, be sure to make each student to achieve accurate in English. Therefore, attention should be paid to distinguish and imitate the right pronunciation and in tonation from the beginning. On this basis, improve listening and speaking to receive good results.

Create a certain listening and speaking environment. Listening and speaking is a kind of language communication. There is not a foreign language environment or some listening, said conditions, rely on is difficult to single handedly convergence. Of course, modern science for us provides a recording machine tools, we can the text, dialogue and the Sino foreign finished tape recorded allowing students to repeatedly listen and imitate, also allows students to record their oral composition and retelling, carefully hearing and found the problem, timely rectification. In the classroom teaching, as much as possible to encourage students to language is a habit, no repeated practice and practice difficult to produce skilled skills. Learn to concentrate on feelings, as long as you can achieve the exchange of ideas, making mistakes is unavoidable, wrong is progress and correct it. Practice said, and practice listening, in the authentic language environment to practice, can make considerable progress.

Start with the normal hearing training. "Said" and "back" combined.

At the beginning, the laborious reads the tape, let the students listen to the tape, after listening, let students speak the sentence as much as possible. Then, students imitate recording in pronunciation and intonation. Constantly repeat the sentence which students do not learn. Now students can imitate say substantially correct language so far. further weather and the voice on the tape synchronization, said. First make students be familiar with the text and the article with the recording synchronized. The establishment of self-confidence can gradually decrease the difficulty of appropriately.

After the studen ts learn to say, and then to carry the. Take dictation to toss about a recording to read loudly, achieve the basic degree will recite. "Back" on improving listening comprehension has great role, such as asking everyday weather, asking fordirections, asking time and so on, which have certain format and sentence pattems, the news back some time later, the students will be familiar with its style and common sentence pattems, is relatively easy to understand recording content, and sometimes even better than recording voice. After going on to listen to a few words of a sentence in front to say in advance exactly behind some words, or listen to a few words before the next sentence. At this point, the tension relieves, or basically eliminates. A relaxed mood can make the level increases, should understand also can understand.

Listen and write combined.

When you start to train "listen" and "write", let the students exercise their own writing on the listening test material. First listen to a certain section of the content from the beginning to the end of the first paragraph, to guide the students to understand the content of the first paragraph and sentence, and then a sentence repeatedly listen to the unit. Make clear a sentence from a few words, the Lord, predicate, object is what word etc. Next, each listen again to teach students to understand the words one by one in order to write on a piece of paper, arranged in a sentence, listen to don't understand the words to empty. For students with low En glish proficiency, it is necessary to listen again and again the places where they do not understand. In this case, encourage them to write the words they understand to make clear exactly how many word they don't understand.

"Listen" and "write" in practice after a period of time, have a higher ability of the students, a little bit difficult to ask short audible. For the unfamiliar words encountered in the passage, students have to listen to to imitate the tapes, accurately grasp the pronunciation of the syllables. Because only the 
pronunciation of the individual syllables is accurately grasped, and then read out and try to spell out some words according to grammar and pronunciation knowledge, to find the dictionary. Because the correct answer often needs to be found repeatedly, when dictation leaves full of room for revision. For the words that the dictation is not out, it is suggested that the students cannot listen to the words of the article to understand the overall content of the article. In the case, the isolation to annoy a word, 100 think not to get its solution, but if with the sentence, the whole message are linkedto understand, thinking on the wide, often also know is what part of speech and how to spell it. This exercise requires students to have the full and patient basis, and the teacher should decide the method according to the actual situation.

Listening training needs to be concentrated, so the time arrangement is appropriate for the best time of every day. Listening is a natural skill, for a period of time every day. Not three days of fishing, two days of the net, cannot listen to after a period of time, just a half a year away.

Teach students a certain listening skills to improve their listening skills .

Combined title to predict the bearing material. This requires that students should be skilled at using their own knowledge to the hearing material content to guess, and then, the teacher can make students put forward what they think the text is about.

Combined with the material behind the exercise topic speculation. In a step backed by quick browse of material practice, make students master some clues for the listening material, combined with the step of speculation, enable students to guess more accurately.

Listen to the passage. In the process of listening to the passage, students must not answer the question according to an individual word or sentence, the principal clues are often in the end of the passage.

Simple records. The teacher wants to let the students listen to the passage of the middle school will listen to the edge record, especially to hear the number and the comparison word writes down.

\section{Pay attention to the supplementary of extra-curricular knowledge}

Contact material, selection of hearing material. The content of the listening materials often involves in Britain and the United States, politics, economy, culture, history, geography, customs and common sense of life. Therefore, ext racurricular background knowledge on listening comprehension of a great help, which a certain extent can reduce dependence of the listener to voice. In teaching, according to the contents of the text, the differences in the culture of the West and the east and the cultural background of China and the United States of America should be paid more attention to, such as juniorhigh school English book 2 (on) un it 10 which in troduces the knowledge about the music and the band, teachers add words about music style and types of students on these more interested in memory effect is better.

Secondly, according to the analysis of the information on the listening test, listening tests of and situational response problems and the written part of the examination of vocabulary, grammar and sentence pattems exchange and translation of the correlation coefficient of the fourth question in more than $70 \%$, and voice and text read the title of the correlation coefficient in more than $60 \%$, and Gestalt fill empty title of correlation coefficient minimum, (没有找到not only的部分以及动词) but also reached the $57.54 \%$ and $49.45 \%$. Data shows that listening and written expression ability has a close relationship, and hearing examination cannot only test students' listening ability, can also test the ability. Then, the test of targeted training is very necessary.

English listening is a fundamental course, in the study to maximize the enthusiasm of the students, which requires that teachers take different training contents and methods according to the specific circumstances.. If the students can obtain new knowledge and new experience in every listening training, they will be interested in listening. The best teaching effect can be produced only when students take the initiative to participate. In a word, the cultivation of the ability of English listening is a process of gradual and repeated practice, the improvement of students' English listening ability is not 
an ovemight thing, only under the joint efforts of teachers and students, constantly repeat practice to constantly improve the students' listening ability.

Effective use of extra-curricular time to strengthen the students' listening training. Extracurricular activity is a key teaching aid, which is conducive to stimulate interest, broaden their horizons, develop intelligence and personality, and cultivate listening and speaking skills. This is the auxiliary of classroom listening, and if it can be combined with the classroom listening training, it will play a very important role. The teacher plays the role of guidance and supervision. Use extra-curricular time to mobilize the interest and en thusiasm of students' listening, expand the studen ts' knowledge to improve listening ability. It can be started specifically from the following 4 points :

1) The teacher asks the students to listen to the text at home.This is the most basic link.Students through listening, practice makes perfect, can be familiar with the content of the text, also can imitate the intonation of the British and American people, so as to enhance their listening.

2) Some extra-curricular listening assignments are appropriately arranged.Teachers can buy or record some of the same ty pe with the same level of difficulty of the text, and give the studen ts to spare time to listen to. But must pay attention to the layout of some help in the listening comprehension of the topic, for example, choice, judgment and fill in the missing words etc.) and timely check the answers, so that they can be in a certain extent to improve the students' listening.

3) To carry out reading contest after school time. Before the game, make the thorough preparation, prompting the students to listen to more imitate the demonstration of the British and American people read loudly. The way of the game is that everyone should open the mouthin order to improve the students distinguish right pronunciation and intonation. The selected reading materials do not necessarily represent identical, each chosen, so that the students can hear the contents of a variety of themes, tone of voice, which can broaden their horizons. If the teacher can make the demonstration reading, the effect is better.

4) Some listening competitions. Take the class as the unit, each class sends some students to participate in the competition. To listen to the competition to take the form of a written answer. The top one or two, three prizes and award, which can also promote the improvement of students' hearing.

Teachers can also org anize English comer. English corner is a most popular activities, its purpose is to for the entire school student provide an after-school places and condition for improving English communicative competence, make up for the lack of classroom teaching, promote the transformation of students' knowledge about skills. As a kind of active form which can improve the oral expression ability, English corner is getting more and more attention and affection.

\section{Conclusions}

Listening is part of English learning process. But no one can disregard the significance of the process. This is the most obscure in the whole process, a lot of students who are learning Englishis facing a lot of problems. This paper discusses several factors that affect the listening of students. It firstly analyzes the cause and then finds out the solution. In language learning, apractice is always an effective way, so students can use good English learning environment. In addition, there is an applicable method to try to find out the details of the learning without attention. These will stimulate their interests in English listening, and help them enhance their confidence. In short, the improvement of listening ability is listening, and only listening to the level of listening to the more practice, listening to the level to gradually improve. And improving the listening level can lie the foundation for the training of high quality English talents for the development of the listening and speaking.

\section{References}

[1] Zhifen Luo. "Some mistakes and Countermeasures in the teaching of junior middle school listening," 2009.4. 
[2] Teng Teng. "' in English Listening Teaching in middle school, high school English "friends" (late).2010 01 .

[3] Yang Li."the Crazy English Listening Training Act", the China Record Corp.

[4] Dingfang Shu. "modern foreign language teaching --- theory, practice and method". Shanghai foreign language education press.

[5] Guofeng Shi. "How to improve students' listening strategies", "China education innovation and development", 2002.03. 